Journal Article

\title{
Formation of chitosan nanoparticles to encapsulate krill oil (Euphausia superba) for application as a dietary supplement
}

Haidera, J., Majeeda, H., Williams, P.A., Safdara, W. and Zhonga, F.

\section{Recommended citation:}

Haidera, J., Majeeda, H., Williams, P.A., Safdara, W. and Zhonga, F. (2016), 'Formation of chitosan nanoparticles to encapsulate krill oil (Euphausia superba) for application as a dietary supplement', Food Hydrocolloids, vol 63, pp.27-34. DOI: 10.1016/j.foodhyd.2016.08.020. 


\section{Formation of chitosan nanoparticles to encapsulate krill oil (Euphausia} superba) for application as a dietary supplement

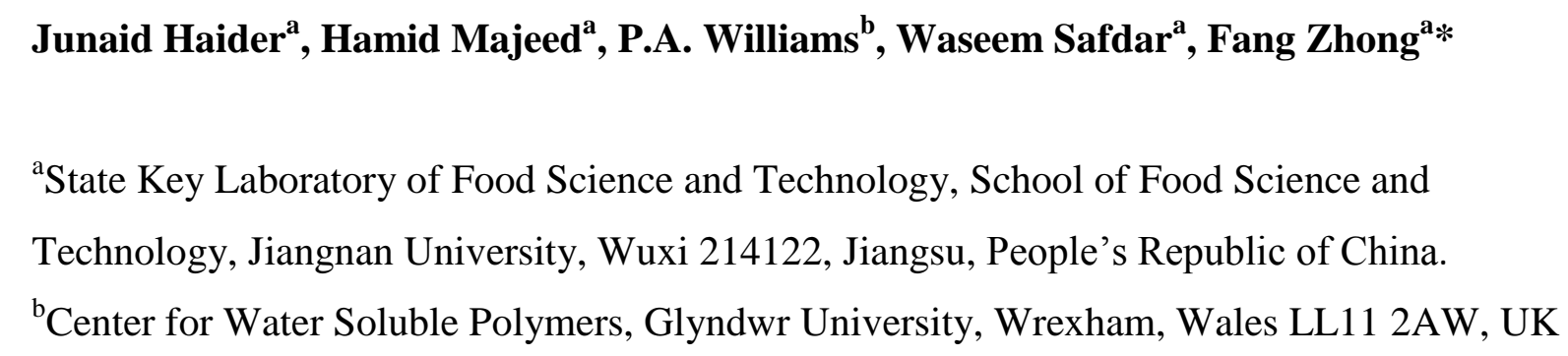

\section{Formation of chitosan nanoparticles to encapsulate krill oil (Euphausia superba) for application as a dietary supplement}


Encapsulation of krill oil (KO), a rich source of eicosapentanoic (EPA) and docosahexanoic acid (DHA) was carried out in chitosan-TPP (tripolyphosphate) nanoparticles using a newly developed two-step process (i.e, formation of emulsion and later electrostatic interaction of chitosan with TPP). The encapsulation of $\mathrm{KO}$ in chitosan nanoparticles (CSNPs) was confirmed by using Fourier transform infrared spectroscopy (FTIR), X-ray diffraction (XRD) and Thermo gravimetric analysis (TGA) techniques. $9-25$ and $33-59 \%$ respectively, when the initial $\mathrm{KO}$ content was in the ratio of $0.25-1.25$ g/g of Chitosan. Bulk KO showed less protection to oxidation and showed more formation of hydroperoxides during first week as noted by FTIR. However, KO loaded CSNPs showed better prevention of $\mathrm{KO}$ towards oxidation with less hydroperoxide formation even after two enhance their usage in the Food and Pharmaceutical industries.

Key Words: Krill Oil, Fourier transform infrared spectroscopy (FTIR), X-ray diffraction

(XRD), Thermo gravimetric analysis (TGA), Oxidative stability

\section{Introduction}

54 Antarctic Krill (Euphausia superba) has recently emerged as a potential and rich alternative 55 source of long chain omega-3 polyunsaturated fatty acids (LC $\omega$-3 PUFAs) besides the algal and fish oils to be substituted as a dietary supplements. Krill oil (KO) contains long chain omega-3 polyunsaturated fatty acids (LC $\omega-3$ PUFAs), namely eicosapentaenoic acid (EPA, 20:5) and docosahexaenoic acid (DHA, 22:6) (Grandois, Marchioni, Minjie Zhao, Ennahar, \& Bindler, 2009). The fatty acids in fish oil are stored as triglyceride, whereas in KO approximately $30-65$ 
$\%$ of the fatty acids are predominantly incorporated into phospholipids (Schuchardt et al., 2011; Tou, Jaczynski, \& Chen, 2008). The particular and unique amphiphilic structural arrangement of phospholipids provides KO with a much better bioavailability (Schuchardt et al., 2011). Moreover, KO contains naturally occurring powerful antioxidants mainly astaxanthin (Deutsch, 2007; Tou et al., 2008). Various researchers recommend use of KO to prevent chronic disorders like cardiovascular diseases, endocannabinoide, poor infant development, non-alcoholic fatty liver disease, premenstrual syndrome, inflammation and certain cancers. This preventive effect was credited to the synergistic action between KO constituents LC $\omega-3$ PUFAs, phospholipids and astaxanthin (Deutsch, 2007; Sampalis et al., 2003; Tur, Bibiloni, Sureda, \& Pons, 2012). However, its limited solubility in water and rapid instability to oxidation had made it difficult to achieve these benefits (Bustos, Romo, Yáñez, Díaz, \& Romo, 2003).

To avoid limited solubility (Dispersibility in aqueous media), and the oxidative instability of lipophilic compounds like $\mathrm{KO}$, various researchers encapsulate them in protein and carbohydrate based matrices (Ilyasoglu \& El, 2014; Zimet \& Livney, 2009). In addition to the above mentioned benefits, nanoencapsulation of lipophilic compounds also increased their bioavailability (Fathi, Mozafari, \& Mohebbi, 2012). However, protein and polysaccharides that have been used widely to encapsulate lipophilic compounds play a key role in attaining the benefits (Chen \& Subirade, 2005; Wang et al., 2006). For example, Majeed et al, prepared clove oil loaded nanoemulsions using modified starch and Tween 80 based surfactants and attained controlled release of oil from starch based nanoemulsions. However, Tween 80 adsorbed onto the droplet and failed to provide the desired release of oil (Majeed et al., 2016).

Chitosan (CS), a cationic polysaccharide that has been used widely for encapsulation and delivery of lipophilic compounds due to its biodegradability (enzymatically degraded (Lysozyme) into fragments suitable for renal clearance), biocompatibility, non-antigenicity and low toxicity (Malafaya, Silva, \& Reis, 2007). Recently, researchers used a two-step emulsion and ionic-gelation method to produce CS-TPP nanoparticles due to its simplicity and non-toxicity for targeted delivery of bioactives (Malafaya et al., 2007; Yang et al., 2011). In the two step, emulsion ionic-gelation procedure the latter involves electrostatic interaction between cationic groups of CS and anionic groups of TPP (Calvo, Remuñán-López, Vila-Jato, \& Alonso, 1997; Kawashima et al., 1985; Yang et al., 2011). The electrostatic interaction between cationic groups of CS and anionic groups of TPP occurred by inter and intramolecular bonds (Calvo et al., 1997; Kawashima et al., 1985; Yang et al., 2011). Ionic-gelation based CSNPs have been used widely for the encapsulation, and targeted delivery of proteins (Kawashima et al., 1985; Xu \& Du, 2003), essential oils (Hosseini, Zandi, Rezaei, \& Farahmandghavi, 2013; Keawchaoon \& Yoksan, 2011), drugs (Wang et al., 2006; Wu, Yang, Wang, Hu, \& Fu, 2005), vitamins and nutrients (Chen \& Subirade, 2005; Yoksan, Jirawutthiwongchai, \& Arpo, 2010). Keawchaoon and Yoksan revealed successful encapsulation of carvacrol in CS-TPP particles with extended shelf life and well retained functional properties (Keawchaoon \& Yoksan, 2011). Similarly, Hosseini et al, prepared oregano oil loaded CS-TPP nanoparticles by an additional step of oil-inwater emulsification prior to solidification of these droplets by CS \& TPP (Hosseini et al., 2013).

100 They confirmed regularly distributed, spherical shaped particles having size $40-80 \mathrm{~nm}$ with slow release characteristics. They reported more than $80 \%$ release of oregano oil that was attributed to greater surface volume ratio due to smaller particle size. On the other hand, nanocapsules due to larger size reduced the surface volume ratio and ultimately influence the access of digestive enzyme, dispersibility of their products and finally influenced the efficacy of delivery system (Kim, Diab, Joubert, Canilho, \& Pasc, 2016; Majeed et al., 2016). However, 
loading of KO having a distinctive chemical structure of LC $\omega-3$ PUFAs into CSNPs at a nanolevel size has not been elucidated. Therefore, the current study focuses on the fabrication, characterization and oxidative stability of KO loaded in CSNPs by two step process: oil-in-water emulsification, and ionic gelation (CS \& TPP).

\section{Materials and methods}

\subsection{Materials}

Antarctic krill oil contained $\sim 40 \%$ total phospholipid, $\sim 28-30 \%$ total omega-3 fatty acids and $\leq 200 \mathrm{mg} / \mathrm{kg}$ astaxanthin as stated by the manufacturer (Hutai Biopharm Inc. (Sichuan, China). Partially deacetylated chitosan (CS; degree of deacetylation of $91.5 \%$ ), with average molecular weight of $100 \mathrm{kDa}$ derived from crab shells was obtained from Golden-Shell Biochemical Co., Ltd. (Hangzhou, China). CS is a weak polyelectrolyte with a pKa value around 6.5, which is positively charged in acidic conditions (Fan, Yan, $\mathrm{Xu}, \& \mathrm{Ni}, 2012$ ). Tween 80, glacial acetic acid, Sodium tripolyphosphate (TPP) and all other chemicals used were of analytical grade, purchased from Sinopharm Chemical Reagent Co., Ltd., China. Double distilled water was used throughout this study.

\subsection{Preparation of KO-loaded CSNPs}

KO-loaded CSNPs were prepared using a modified version of the method described by (Calvo et al., 1997) and (Hosseini et al., 2013). A schematic illustration representing the CSNPs preparation procedure is shown in Fig. 1. Briefly, CS solution $1.5 \%(\mathrm{w} / \mathrm{v})$ was prepared by agitating CS in an aqueous acetic acid solution $1 \%(\mathrm{v} / \mathrm{v})$ at ambient temperature $\left(25-28{ }^{\circ} \mathrm{C}\right)$ for $24 \mathrm{~h}$. The CS solution was centrifuged at $8000 \mathrm{rpm}$ for $20 \mathrm{~min}$, the supernatant was filtered through a $0.8 \mu \mathrm{m}$ pore size syringe filter. Tween $80(0.5 \mathrm{~g}$, hydrophilic-lipophilic balance $=15)$ was added as a surfactant to the CS solution $(40 \mathrm{~mL})$ and the mixture was stirred at $45^{\circ} \mathrm{C}$ for $2 \mathrm{~h}$ to obtain a homogeneous solution. KO was gradually dropped into the aqueous CS solution (40 $\mathrm{mL}$ ) and the system was homogenized using an Ultra-Turrax (T25, Ika-Werke, Staufen, Germany) at a speed of 13,000 rpm for $1 \mathrm{~min}$ and 16,500 for $2 \mathrm{~min}$. The solution was positioned in an ice-bath to prevent heating. The content of $\mathrm{KO}$ was varied $(0,0.15,0.30,0.45,0.60$ and $0.75 \mathrm{~g})$ to obtain different weight ratios of CS to KO (1:0, 1:0.25, 1:0.50, 1:0.75, 1:1.00 and 1:1.25 respectively). Subsequently, TPP solution $(0.5 \% \mathrm{v} / \mathrm{v}, 40 \mathrm{~mL})$ was then added drop wise into the $\mathrm{o} / \mathrm{w}$ emulsion under continuous stirring and was agitated for $40 \mathrm{~min}$. The particles formed were collected by centrifugation at $10,000 \times \mathrm{g}$ for $30 \mathrm{~min}$ at $20{ }^{\circ} \mathrm{C}$ and washed several times with water to remove or wash off excessive KO. Eventually, the wet particles were dispersed in $25 \mathrm{~mL}$ water by ultrasonication to produce a homogeneous suspension. Ultrasonication was performed using a (Jy98-IIIDN, 20 kHz, Ningbi Scientz Biotechnology Co., Ltd., Ningbo, China) sonicator for $2 \mathrm{~min}$ in an ice bath. The suspensions were immediately freeze-dried at $-35{ }^{\circ} \mathrm{C}$ for $72 \mathrm{~h}$ and were stored in dry conditions at $25{ }^{\circ} \mathrm{C}$.

\subsection{Characterization of KO-loaded CSNPs}

\subsubsection{Z-average diameter and $\zeta$-potential measurements}

The z-average diameter and the uniformity of particles in dispersion (particle size distribution) that is being measured as polydispersity index (PDI) for KO-loaded CSNPs were investigated by dynamic light scattering (DLS) using the Zetasizer Nano ZS ${ }^{\circledR}$ (Malvern 
Instruments, Worcestershire, U.K.). To avoid multiple scattering effects, the nanoparticles were diluted 100-fold with purified water, placed in a cuvette and agitated well prior to measurements. Refractive indices of 1.45 for $\mathrm{KO}$ and 1.330 for water were used. $\zeta$-potential was determined by Laser Doppler Velocimetry using the Zetasizer Nano $\mathrm{ZS}^{\circledR}$ at a scattering angle of $173^{\circ}$ at $25^{\circ} \mathrm{C}$. The diluted nanoparticles were placed in a folded capillary electrophoresis cell with count rate between 100 and $300 \mathrm{Kcps}$ as described by Zainol et al. (Zainol et al., 2012). All the tests were performed in triplicate.

\subsubsection{Morphology of KO-loaded CSNPs}

The morphological characterization of the nanoparticles was done using SEM (Hitachi S4800 , Japan) at an accelerating voltage $2 \mathrm{kV}$. The powders were sprinkled onto double-backed cellophane tape attached to an aluminium stub before coating with gold-palladium in an argon atmosphere.

\subsubsection{Characterization using FTIR, TGA and XRD}

The infrared spectra of all samples were obtained using a Thermo Fisher Scientific Inc., Nicolet iS10, FTIR spectrometer with $\mathrm{KBr}$ accessory. This instrument was operated with Nicolet OMNIC software (Version 8.2). For KO spectral acquisition, the liquid sample $(\approx 2 \mu \mathrm{L})$ was deposited on a $\mathrm{KBr}$ disk. The spectra were obtained using 16 scans at a resolution of $4 \mathrm{~cm}^{-1}$ over the frequency range of $4000-400 \mathrm{~cm}^{-1}$. Before running each sample a background spectrum was obtained in air.

Contact angle was used to determine the interaction between $\mathrm{KO}$ and nanoparticles with sessile drop method. Briefly, $\mathrm{KO}(3 \mu \mathrm{L})$ was carefully dropped with a dosing rate of $0.5 \mu \mathrm{L} / \mathrm{s}$ onto the slides $(20 \mathrm{~mm} \times 50 \mathrm{~mm} \times 1 \mathrm{~mm})$ using $2 \mathrm{~mL}$ micrometer syringe (KDL Corp., Shanghai, China). The measurements were carried out in open air with relative humidity $(30 \%)$ and at a room temperature of $25^{\circ} \mathrm{C}$. Both left and right contact angles expressed in degrees were automatically calculated from the digitalized image software belonging to the equipment (DataPhysics Instruments $\mathrm{GmbH}$, OCA15EC, Germany). Measurements were taken in triplicate of each sample.

TGA was performed using a TGA/DSC 1 STARe (Mettler-Toledo, Switzerland) $25-600{ }^{\circ} \mathrm{C}$ with a heating rate of $10{ }^{\circ} \mathrm{C} / \mathrm{min}$ under nitrogen atmosphere. Each freeze-dried sample $6-10 \mathrm{mg}$ was placed in the TGA furnace. The derivative thermogravimetric curves (DTG) and the first derivative of TG curves were calculated.

XRD patterns of packing materials were assessed by X-ray diffraction using a (Bruker AXS D8, Germany) diffractometer. The operation conditions were $40 \mathrm{kV}$ and $40 \mathrm{~mA}$ with $\mathrm{Cu} \mathrm{K} \alpha$ radiaton $(\lambda=1.5406 \AA)$. Samples were scanned in the $2 \theta$ range of $5^{\circ}-50^{\circ}$ at a speed of $0.03^{\circ}$ per second.

\subsection{Determination of loading capacity (LC) and encapsulation efficiency (EE)}

The content of KO-loaded CSNPs was determined by TGA/DTG. Freeze dried CSNPs and KO-loaded CSNPs were placed in TGA furnace at $25-600{ }^{\circ} \mathrm{C}$ with a heating rate of $10{ }^{\circ} \mathrm{C} / \mathrm{min}$ under nitrogen atmosphere and the weight loss percentage, obtained from TGA thermograms was used to determine the content of KO-loaded CSNPs. The loading capacity of KO $(\mathrm{g} / 100 \mathrm{~g}$ of sample) and encapsulation efficiency of $\mathrm{KO}(\mathrm{g} / 100 \mathrm{~g}$ of sample) were thus calculated from eqs. (1) and (2) respectively.(Yoksan et al., 2010) 
LC $(\%)=\frac{\text { wight of loaded KO }}{\text { Weight of sample }} \times 100$

$\mathrm{EE}(\%)=\frac{\text { wight of loaded KO }}{\text { Weight of initial KO }} \times 100$

\subsection{Storage conditions}

For the lipid oxidation experiments, five grams of bulk oil and freeze-dried KO-loaded CSNPs were placed in $20 \mathrm{ml}$ loosely capped amber glass bottles. Samples were stored at $45{ }^{\circ} \mathrm{C}$ for 4 weeks. The extent of lipid oxidation was investigated in terms of lipid hydroperoxide. All the experiments were carried out in duplicate.

\subsubsection{Determination of lipid oxidation}

In this study, lipid hydroperoxides, the primary oxidation products was monitored by FTIR (Guillén \& Cabo, 1999, 2002). Each band frequency was obtained automatically from the instrument software command "find peaks" with an adequate threshold value near $85 \%$. The functional group vibration mode of each band was made by comparison with software spectral library as well as with literature data and similar experimental conditions of FTIR was applied for sample acquisition as utilised to confirm the loading of KO in CSNPs (See section 2.3.3).

\section{Results and discussion}

\subsection{Shape, size and surface charge of KO-loaded CSNPs}

KO-loaded CSNPs were prepared through the formation of oil droplets (including KO) and droplet solidification. The KO droplet formation in CS solution was achieved using the $\mathrm{O} / \mathrm{W}$ emulsion technique. The solidification of each droplet was extended by ionic cross-linking of ammonium groups of CS molecules surrounding the KO droplet and phosphate groups of TPP.

The surface morphology of CSNPs and KO-loaded CSNPs were observed by SEM. Fig. 2 (a, b) shows the CSNPs size varied between 100 - $300 \mathrm{~nm}$ that correlates with the findings of Yoskan (Yoksan et al., 2010). For KO-loaded CSNPs, the aggregations were also seemed that might be due to remaining $\mathrm{KO}$ around the particles with an average range of $80-130 \mathrm{~nm}$ (Fig. 2-c, d).

The z-average diameter and PDI of CSNPs and KO-loaded CSNPs were examined by dynamic light scattering (DLS). Fig. 3 shows that the z-average diameter and PDI of CS particles were about $\sim 252 \mathrm{~nm}$ and 0.199 , respectively. The z-average diameter of KO-loaded CSNPs were in the range of $229.5-182.4 \mathrm{~nm}$. With increasing ratio of $\mathrm{KO}$, the $\mathrm{z}$-average diameter decreased (Table 1). The possible reason behind this reduction in particle size might be the coemulsifying properties of the oil constituents in the presence of surfactant that reduces the interfacial tension as various researchers reported this phenomenon for essential oil loaded nanoemulsions (Majeed, Antoniou, \& Fang, 2014; Terjung, Löffler, Gibis, Hinrichs, \& Weiss, 2012). However, the agglomeration and/or swelling of KO-loaded CSNPs in water were lower than those of CS particles. The obvious difference in the agglomeration of two nanoparticulate systems is the formation mechanism. The CS particles are formed by the electrostatic interaction of CS and TPP and their size will depend on how the molecules were mixed together. On the other hand, KO-loaded CSNPs are formed by the adsorption of CS onto the KO droplets. The lower agglomeration in KO-loaded CSNPs might be due to hydrophobic KO molecules that forced it to 
entrap inside (Keawchaoon \& Yoksan, 2011; Yoksan et al., 2010). The interesting fact about KO is that it possesses a large proportion of marine phospholipids (about $40 \%$ ) bonding with LC $\omega-3$ PUFAs like EPA and DHA (Zhu, Zhuang, Luan, Sun, \& Cao, 2015). Similarly, Shen and Lu et al. reported small z-average diameter of nanoparticles that can be credited to phospholipids in $\mathrm{KO}$, having substantial inherent emulsifying power (Lu, Nielsen, Baron, Jensen, \& Jacobsen, 2012; Shen, Bhail, Sanguansri, \& Augustin, 2014).

In addition, $\zeta$-potential of CSNPs gave a positive charge of $+37.7 \mathrm{mV}$ as shown in Fig. 3 . The positive surface charge arises due to ammonium groups of $\mathrm{CS}$. With loading of $\mathrm{KO}$, the $\zeta$ potential was decreased to $+26.6 \mathrm{mV}$. This reflects the CSNPs surface with increasing KO content. The reduction in $\zeta$-potential value was related to the number of TPP to CS charge groups as evident by the findings of (Antoniou et al., 2015). However, this reduction might be due to shielding effect of protonated $-\mathrm{NH}_{2}$ group by $\mathrm{KO}$ on CSNPs. Several studies have reported that $\zeta$-potential values of CSNPs was reduced when drugs, i.e., ascorbic acid (Jang \& Lee, 2008) and eugenol were (Woranuch \& Yoksan, 2013) incorporated. This demonstrated that $\zeta$-potential value influenced reciprocally with increased drug content.

\subsection{Characterization of KO-loaded CSNPs}

CSNPs loaded with KO were characterized by Fourier Transform Infrared spectroscopy (FTIR). The results confirmed the presence of $\mathrm{KO}$ with characteristic peaks at $3416 \mathrm{~cm}^{-1}(\mathrm{OH})$, $3012 \mathrm{~cm}^{-1}$ (=C-H stretching), $3000-2800 \mathrm{~cm}^{-1}$ (C-H stretching), $1740 \mathrm{~cm}^{-1}$ (C=O stretching band), $1465 \mathrm{~cm}^{-1}$ ( $-\mathrm{CH}_{2}-$ bending), $1379 \mathrm{~cm}^{-1}$ (- $\mathrm{CH}_{3}$ bending), $1091 \mathrm{~cm}^{-1}$ (CO stretching), 971 $\mathrm{cm}^{-1}(\mathrm{C}=\mathrm{C}$ stretching band $)$ as shown in Fig. 4 a.

However, CSNPs showed characteristics bands at $3450 \mathrm{~cm}^{-1}(\mathrm{OH}), 2927 \mathrm{~cm}^{-1}(\mathrm{CH}$ stretching), $1640 \mathrm{~cm}^{-1}$ (amide I), $1543 \mathrm{~cm}^{-1}$ (amide II), $1155 \mathrm{~cm}^{-1}$ (P=O), $1097 \mathrm{~cm}^{-1}$ (COC) and $891 \mathrm{~cm}^{-1}$ (pyranose ring) that suggests the complex formation between CS and TPP as a result of electrostatic interaction Fig. 4b (Bhumkar \& Pokharkar, 2006; Xu \& Du, 2003). Moreover, FTIR confirmed the incorporation of KO in CSNPS (Fig. 4 c-g) by comparing with characteristic peaks in the KO spectra. The occurrence of characteristic peak at same wave number in $\mathrm{KO}$ loaded CSNPs indicating no interaction with chitosan. Similarly, non-interaction behaviour of chitosan (hydrophilic) with oregano oil (hydrophobic) has earlier been reported by Hosseini et al when incorporated in CS-TTP nanoparticles (Hosseini et al., 2013). Further, this interaction was investigated using contact angle measurement and also showed no interaction between $\mathrm{KO}$ and CSNPs as shown in Figure Fig. 5. The contact angle of KO and CSNPs with air was 38.35 and 25.84, respectively as shown in Fig. 5a \& b. However, in case of increasing ratios of KO in loaded CSNPs the contact angle increased $(26.28-36.46)$ that suggests increased hydrophobicity of KO (Fig. 5 c-g). On the other hand, with maximum KO loaded CSNPs (1:1 \& 1: 1.25) showed significant increase in contact angle (10 degree rise). Whereas, at lower ratios (1: $0.25-1: 0.75)$ of KO loaded CSNPs the contact angle was quite same (26.28 \& 31.21) as appeared in KO with unloaded CSNPs (Fig. c,d). The possible reason behind this increase in contact angle at highest CS:KO mass ratios is the exposure of excessive oil to standard drop of $\mathrm{KO}(3 \mathrm{ul})$ used during this experimental procedure that resulted in increased hydrophobicity. These findings revealed that CS and CSNPs showed no interaction with KO. Contact angle measurement has already been used by variety of researchers to explain the interaction behaviour of hydrophobic and hydrophilic compounds (Liu et al., 2016; Shamsijazeyi et al., 2014).

On the other hand, the increase in $\mathrm{CH}$ stretching peak intensity at $2869-2974 \mathrm{~cm}^{-1}$ reflects the location of $\mathrm{KO}$ in the CS matrix. These results were further strengthened as the increase in $\mathrm{CH}$ stretching peak intensity was observed with increasing $\mathrm{KO}$ content. Therefore, we can 
consider $\mathrm{CH}$ stretching as a strong indicator of $\mathrm{KO}$ encapsulation in any matrix (Vongsvivut et al., 2012; Zhao, Wei, Liu, \& Liu, 2014). Thus, emulsion and later electrostatic interaction of CS with TPP, a two-step process successfully encapsulated KO in CSNPs. (Section 3.3)

TGA has been used widely by a variety of researchers to confirm the weight change of material that is monitored as a function of temperature to evaluate its thermal stability (Yoksan et al., 2010). In our case, the degree of weight loss for CS alone and KO loaded CSNPs decreased with increasing temperature from 25 to $600{ }^{\circ} \mathrm{C}$ as shown in Fig. 6A. KO degradation showed one level of weight loss Fig. 6A (a). Whereas, CS and KO loaded CSNPs showed two (Fig. 6A-b) and three levels of weight loss Fig. 6A (c-g). Nam et al. reported the first and second level of weight loss for CS nanofibers that showed temperature ranges from 56 to $115^{\circ} \mathrm{C}$ and $182-310$ ${ }^{\circ} \mathrm{C}$, which corresponded to evaporation of moisture and decomposition of polymer, respectively (Nam, Park, Ihm, \& Hudson, 2010). The rate of maximum weight loss corresponding to temperature was determined as the decomposition temperature $\left(T_{\mathrm{d}}\right)$, which is clearly observed as a peak in the derivative thermogravimetry (DTG) thermogram, plotted in Fig. 6B. From the DTG thermogram, CSNPs exhibited one level $T_{\mathrm{d}}$ at $247^{\circ} \mathrm{C}$ (Fig. 6B-b). By comparison between CS and KO-loaded CSNPs manifested new $T_{\mathrm{d}}$ range $327-331{ }^{\circ} \mathrm{C}$ (Fig. 6B (c-g), which corresponded to the $T_{\mathrm{d}}$ of KO (Fig. 6B-a). The results confirmed the successful loading of KO into CSNPs. Similarly, Yoksan et al. reported increased thermal stability of successfully encapsulated ascorbyl palmitate in CSNPs (Yoksan et al., 2010). The weight loss percentage at this temperature range was thus used to compute the quantity of loaded $\mathrm{KO}$ (section 3.3)

XRD patterns of CS powder, CSNPs, and KO-loaded CSNPs are presented in Fig. 7. Generally, CS exhibits two peaks at $2 \theta$ of $10^{\circ}$ and $20^{\circ}$ (Fig. 7a), showing high degree of crystallinity. After electrostatic interaction with TPP, peak broadening and peak shifts were observed with reduction of peak intensity (Fig. 7b). In addition, a new peak is found in the diffractogram of CSNPs at $2 \theta$ of $23^{\circ}$. These distinct differences reflect the modification in the arrangement of molecules in the crystal lattice stimulated by ionic interaction (Bhumkar \& Pokharkar, 2006; Yoksan et al., 2010). As compared with CSNPs, in the diffraction spectrum of KO-loaded CSNPs the characteristic peaks at $2 \theta$ of $18^{\circ}$ confirmed the presence of KO within CSNPs. Thus, XRD analysis revealed the successful encapsulation of KO in CSNPs as it clearly showed change in the CS-TPP packing structure. So, on behalf of FTIR, TGA, and XRD we can conclude that two steps, emulsion and electrostatic interaction between CS and TPP is suitable for the encapsulation of $\mathrm{KO}$ in CSNPs.

\subsection{Encapsulation efficiency and loading capacity}

The TGA/DTG technique was applied for quantitative analysis of CSNPs in terms of weight loss at temperature ranging from $290-380{ }^{\circ} \mathrm{C}$, corresponding to $T_{\mathrm{d}}$ of $\mathrm{KO}$. The percentage of LC and EE of KO-loaded CSNPs were then calculated using Eqs. (1) and (2), respectively, and are tabulated in Table 1. From TGA results, the percentage of LC was in the range of 8.8 to $24.7 \%$ at 25 to $125 \%(\mathrm{w} / \mathrm{w})$ ratio of KO to CS (Table 1). LC percentage was dependent on initial KO content that was in agreement to the findings of other researchers who reported carvacrol or BSA loading in CSNPs was initial concentration dependent (Keawchaoon \& Yoksan, 2011; Xu $\& \mathrm{Du}, 2003)$. EE of KO ranged from 33.3 to $58.9 \%$. Maximum EE value (58.9\%) was achieved at 1:0.25 (w/w) CS to KO ratio. However, with the increase of KO ratio, EE started to decrease as shown in Table 1. This might be due to saturation of CSNPs with KO (Hosseini et al., 2013; Yoksan et al., 2010), as it possesses a large proportion of marine phospholipids bonded with LCPUFA and astaxanthin. No doubt, large proportion of phospholipids (about $50 \%$ ) in KO bounds with DHA, EPA and astaxanthin, which enhanced the solubility of these constituents in lipid 
phase that consequently reduced its diffusion outside the nanoparticles (Zhu et al., 2015). The reduction in EE with increasing $\mathrm{KO}$ content suggests its loading in CSNPs is limited.

In addition to EE, LC was determined by FTIR using the $\mathrm{CH}$ stretching peak to determine the content of KO in CSNPs. The CH stretching peak at $2925 \mathrm{~cm}^{-1}$ and the pyranose peak at 891 $\mathrm{cm}^{-1}$ were used as representative peaks of $\mathrm{KO}$ and $\mathrm{CS}$, respectively. The $\mathrm{CH}$ stretching to pyranose peak $\left(I_{2925} / I_{891}\right)$ is shown in Table 1. CSNPs showed an $I_{2925} / I_{891}$ value of 0.91 and for KO-loaded CSNPs, the value of $I_{2925} / I_{891}$ was greater than 0.91 suggesting successful loading of $\mathrm{KO}$ in the nanoparticles. KO-loaded CSNPs with initial KO content $(0.25-1.25 \mathrm{~g} / \mathrm{g})$ of CS showed $I_{2925} / I_{891}$ values in the range of $1.14-1.81$. The value of $I_{2925} / I_{891}$ increased with increasing initial KO content. However, KO-loaded CSNPs with an initial KO content of $1 \mathrm{~g} / \mathrm{g}$ of CS provided the maximum value of $I_{2925} / I_{891}$ as shown in Table 1 . These results confirmed the findings of TGA and we can conclude that the optimal weight ratio of CS to KO was 1:1.

\subsection{Oxidative stability}

The oxidative stability of bulk $\mathrm{KO}$ and $\mathrm{KO}$ containing CSNPs was evaluated using FTIR spectra that were determined after exposure with elevated oxidative stress $\left(45^{\circ} \mathrm{C}\right)$. FTIR spectroscopy has been used earlier to identify change in the functional groups of the sample that undergoes lipid oxidation (Voort, Ismail, Sedman, \& Emo, 1994). Fig. 8 illustrates obvious spectral changes in krill oil spectra as oxidation proceeds. However, peak shift in the ROOH region from $\sim 3416 \mathrm{~cm}^{-1}$ to $\sim 3377$ suggests the formation of hydroperoxides (Fig. 8-A). Whereas change in CO (initial absorption at $\sim 1091 \& \sim 1077 \mathrm{~cm}^{-1}$ and gradual shifting to $\sim 1093 \& \sim 1065$ $\mathrm{cm}^{-1}$ respectively) and trans region confirmed the formation of conjugated trans species $(\sim 971$ cm-1) along with isolated trans absorptions $\left(\sim 969 \mathrm{~cm}^{-1}\right)$ as presented in (Fig. 8-B). In the case of KO containing CSNPS the ROOH peak shift varied with CS-KO weight ratios. For 1:1, it was moved to $\sim 3431$ to $\sim 3404 \mathrm{~cm}^{-1}$ and $\sim 3424$ to $\sim 3389 \mathrm{~cm}^{-1}$ at 1:1.25 ratio (Fig. 8-C). On the other hand, the triglyceride ester group peak shifts showed less dependency to CS-KO weight ratios and it was from $\sim 1741$ to $\sim 1739 \mathrm{~cm}^{-1}$ at 1:1 \& 1:1.25 CS-KO weight ratios as shown in Fig. 8-D.

The occurrence of a larger shift $\sim 39 \mathrm{~cm}^{-1}\left(\sim 3416-\sim 3377 \mathrm{~cm}^{-1}\right)$ in the ROOH band under oxidative stress as shown in Fig. 8 has already been confirmed (Voort et al., 1994). Moreover, there was a shift back to higher wavenumbers $(\sim 3425)$ that might be due to breakdown of hydroperoxides to alcohols as evident by the findings of Gullién \& Cabo and Voort et al. (Guillén \& Cabo, 1999; Voort et al., 1994). In contrast a band shift of $\sim 12 \mathrm{~cm}^{-1}$ of CO groups in the esters and only a slight $\left(1-2 \mathrm{~cm}^{-1}\right)$ shift in cis, conjugated trans, and isolated trans bands occurred. The KO showed an obvious decrease in the $\mathrm{ROOH}$ band and triglyceride ester groups during the first week of storage. KO-loaded CSNPs showed a modest decrease in band shifts even after two weeks of storage that suggests more oxidation prevention of KO in CSNPS.

The oxidation prevention of KO in KO-loaded CSNPs in terms of little change in band shift of $\mathrm{ROOH}$ and triglyceride ester groups under oxidative stress showed less availability of hydroperoxides to convert them back to aldehydes and ketones (Guillén \& Cabo, 2002). Similary Gullién and Cabo also reported a shift of the ROOH band towards lower wavenumbers as oils underwent oxidation, but to a somewhat lesser extent (Guillén \& Cabo, 1999). Thus, it may be postulated that the $\mathrm{ROOH}$ band shift is due to extensive intermolecular hydrogen bonding of hydroperoxides (Russin, van de Voort, \& Sedman, 2003).

\section{Conclusion}

The KO loaded CSNPs were prepared by a two-step, emulsion and later electrostatic interaction of CS with TPP showed average diameter of $80-130 \mathrm{~nm}$ as observed by SEM. The 
loading capacity (LC) and encapsulation efficiency (EE) of $\mathrm{KO}$ in nanoparticles was about 8.8 to $24.7 \%$ and 33.3 to $58.9 \%$, respectively, when the ratio of KO to CS was $25-125 \%$. Moreover, the loading of $\mathrm{KO}$ into CSNPs was confirmed by the increment of $\mathrm{CH}$ stretching peak intensity at $2869-2974 \mathrm{~cm}^{-1}$ (FTIR technique), a degradation temperature of $327-331{ }^{\circ} \mathrm{C}$ (TGA/DTG techniques), and the characteristic peaks at $2 \theta$ of $18^{\circ}$ (XRD technique). Further, CSNPS were successful in preventing the oxidation of KO. The results confirmed the suitability of the emulsion and electrostatic interaction based method for the formation of KO loaded CSNPs with greater EE \& LC that will enhance their usage in food and pharmaceutical industry. But, prior to their industrial usage further research is needed on the sensory perception, bioavailability and protection of encapsulate deterioration during product shelf life.

\section{Acknowledgement}

This work was financially supported by National 125 program 2011BAD23B02; NSFC 31571891 and 31401533; JUSRP 51507 and 11422; 111Project B07029 and PCSIRT0627.

\section{References}

Antoniou, J., Liu, F., Majeed, H., Qi, J., Yokoyama, W., \& Zhong, F. (2015). Physicochemical and morphological properties of size-controlled chitosan-tripolyphosphate nanoparticles. Colloids and Surfaces A: Physicochemical and Engineering Aspects, 465, 137-146.

Bhumkar, D. R., \& Pokharkar, V. B. (2006). Studies on effect of pH on cross-linking of chitosan with sodium tripolyphosphate: a technical note. AAPS PharmSciTech, 7(2), E50.

Bustos, R., Romo, L., Yanez, K., Diaz, G., \& Romo, C. (2003). Oxidative stability of carotenoid pigments and polyunsaturated fatty acids in microparticulate diets containing krill oil for nutrition of marine fish larvae. Journal of Food Engineering, 56(2-3), 289-293.

Calvo, P., Remunan-Lopez, C., Vila-Jato, J. L., \& Alonso, M. J. (1997). Novel hydrophilic chitosan-polyethylene oxide nanoparticles as protein carriers. Journal of Applied polymer science, 63(1), 125-132.

Chen, L., \& Subirade, M. (2005). Chitosan/ $\beta$-lactoglobulin core-shell nanoparticles as nutraceutical carriers. Biomaterials, 26(30), 6041-6053.

Deutsch, L. (2007). Evaluation of the effect of Neptune Krill Oil on chronic inflammation and arthritic symptoms. Journal of the American College of Nutrition, 26(1), 39-48.

Fan, W., Yan, W., Xu, Z., \& Ni, H. (2012). Formation mechanism of monodisperse, low molecular weight chitosan nanoparticles by ionic gelation technique. Colloids and Surfaces B: Biointerfaces, 90(1), 21-27.

Fathi, M., Mozafari, M. R., \& Mohebbi, M. (2012). Nanoencapsulation of food ingredients using lipid based delivery systems. Trends in Food Science and Technology, 23(1), 13-27.

Grandois, J. L. E., Marchioni, E., Minjie Zhao, F. G., Ennahar, S., \& Bindler, F. (2009). investigation of natural phosphatidylcholine sources: separation and identification by liquid chromatography-electrospray lonization-tandem mass spectrometry (lc-esi-ms2) of molecular species. Journal of Agricultural and Food Chemistry, 57(14), 6014-6020.

Guillén, M. D., \& Cabo, N. (1999). Usefulness of the Frequency Data of the Fourier Transform Infrared Spectra To Evaluate the Degree of Oxidation of Edible Oils. Journal of Agricultural and Food Chemistry, 47(2), 709-719. 
Guillén, M. D., \& Cabo, N. (2002). Fourier transform infrared spectra data versus peroxide and anisidine values to determine oxidative stability of edible oils. Food Chemistry, 77(4), 503510.

Hosseini, S. F., Zandi, M., Rezaei, M., \& Farahmandghavi, F. (2013). Two-step method for encapsulation of oregano essential oil in chitosan nanoparticles: Preparation, characterization and in vitro release study. Carbohydrate Polymers, 95(1), 50-56.

Ilyasoglu, H., \& El, S. N. (2014). Nanoencapsulation of EPA/DHA with sodium caseinate-gum arabic complex and its usage in the enrichment of fruit juice. LWT - Food Science and Technology, 56(2), 461-468.

Jang, K.-I., \& Lee, H. G. (2008). Stability of Chitosan Nanoparticles for L -Ascorbic Acid during Heat Treatment in Aqueous Solution. Journal of Agricultural and Food Chemistry, 56, 1936-1941.

Kawashima, Y., Handa, T., Kasai, A., Takenaka, H., Lin, S. Y., \& Ando, Y. (1985). Novel method for the preparation of controlled-release theophylline granules coated with a polyelectrolyte complex of sodium polyphosphate-chitosan. Journal of Pharmaceutical Sciences, 74(3), 264-268.

Keawchaoon, L., \& Yoksan, R. (2011). Preparation, characterization and in vitro release study of carvacrol-loaded chitosan nanoparticles. Colloids and Surfaces B: Biointerfaces, 84(1), 163-171.

Kim, S., Diab, R., Joubert, O., Canilho, N., \& Pasc, A. (2016). Core-shell microcapsules of solid lipid nanoparticles and mesoporous silica for enhanced oral delivery of curcumin. Colloids and Surfaces. B, Biointerfaces, 140, 161-8.

Liu, Y., Xing, L., Zhang, Q., Mu, Q., \& Liu, P. (2016). Thermo- and Salt-Responsive Poly ( NIPAm- Co -AAc-Brij-58 ) Microgels : Adjustable Size, Stability under Salt Stimulus, and Rapid Protein Adsorption / Desorption. Colloid and Polymer Science, 294, 617-28.

Lu, F. S. H., Nielsen, N. S., Baron, C. P., Jensen, L. H. S., \& Jacobsen, C. (2012). Physicochemical properties of marine phospholipid emulsions. JAOCS, Journal of the American Oil Chemists' Society, 89(11), 2011-2024.

Majeed, H., Antoniou, J., \& Fang, Z. (2014). Apoptotic Effects of Eugenol-loaded Nanoemulsions in Human Colon and Liver Cancer Cell Lines. Asian Pacific Journal of Cancer Prevention, 15(21), 9159-9164.

Majeed, H., Antoniou, J., Hategekimana, J., Sharif, H. R., Haider, J., Liu, F., Zhong, F. (2016). Influence of carrier oil type, particle size on in vitro lipid digestion and eugenol release in emulsion and nanoemulsions. Food Hydrocolloids, 52, 415-422.

Malafaya, P. B., Silva, G. a., \& Reis, R. L. (2007). Natural-origin polymers as carriers and scaffolds for biomolecules and cell delivery in tissue engineering applications. Advanced Drug Delivery Reviews, 59(4-5), 207-233.

Nam, Y. S., Park, W. H., Ihm, D., \& Hudson, S. M. (2010). Effect of the degree of deacetylation on the thermal decomposition of chitin and chitosan nanofibers. Carbohydrate Polymers, 80(1), 291-295.

Russin, T. A., van de Voort, F. R., \& Sedman, J. (2003). Novel method for rapid monitoring of lipid oxidation by FTIR spectroscopy using disposable IR cards. Journal of the American 
Oil Chemists' Society, 80(7), 635-641.

Sampalis, F., Bunea, R., Pelland, M. F., Kowalski, O., Duguet, N., \& Dupuis, S. (2003). Evaluation of the effects of Neptune Krill Oil on the management of premenstrual syndrome and dysmenorrhea. Alternative Medicine Review : A Journal of Clinical Therapeutic, 8(2), 171-9.

Schuchardt, J. P., Schneider, I., Meyer, H., Neubronner, J., von Schacky, C., \& Hahn, A. (2011). Incorporation of EPA and DHA into plasma phospholipids in response to different omega-3 fatty acid formulations - a comparative bioavailability study of fish oil vs. krill oil. Lipids in Health and Disease, 10(1), 145.

Shamsijazeyi, H., Miller C. A., Wong M. S., Tour, J. M., \& Verduzco, R.. (2014). PolymerCoated Nanoparticles for Enhanced Oil Recovery. Journal of Applied polymer science 40576, 1-13.

Shen, Z., Bhail, S., Sanguansri, L., \& Augustin, M. A. (2014). Improving the oxidative stability of krill oil-in-water emulsions. JAOCS, Journal of the American Oil Chemists' Society, 91(8), 1347-1354.

Terjung, N., Löffler, M., Gibis, M., Hinrichs, J., \& Weiss, J. (2012). Influence of droplet size on the efficacy of oil-in-water emulsions loaded with phenolic antimicrobials. Food \& Function, 3(3), 290-301.

Tou, J. C., Jaczynski, J., \& Chen, Y.-C. (2008). Krill for Human Consumption: Nutritional Value and Potential Health Benefits. Nutrition Reviews, 65(2), 63-77.

Tur, J. A., Bibiloni, M. M., Sureda, A., \& Pons, A. (2012). Dietary sources of omega 3 fatty acids: public health risks and benefits. British Journal of Nutrition, 107(S2), S23-S52.

Vongsvivut, J., Heraud, P., Zhang, W., Kralovec, J. a., McNaughton, D., \& Barrow, C. J. (2012). Quantitative determination of fatty acid compositions in micro-encapsulated fish-oil supplements using Fourier transform infrared (FTIR) spectroscopy. Food Chemistry, 135(2), 603-9.

Voort, F. R., Ismail, A. A., Sedman, J., \& Emo, G. (1994). Monitoring the oxidation of edible oils by Fourier transform infrared spectroscopy. J. Am. Oil Chem. Soc., 71(3), 243-253.

Wang, L. Y., Gu, Y. H., Zhou, Q. Z., Ma, G. H., Wan, Y. H., \& Su, Z. G. (2006). Preparation and characterization of uniform-sized chitosan microspheres containing insulin by membrane emulsification and a two-step solidification process. Colloids and Surfaces B: Biointerfaces, 50(2), 126-135.

Woranuch, S., \& Yoksan, R. (2013). Eugenol-loaded chitosan nanoparticles: I. Thermal stability improvement of eugenol through encapsulation. Carbohydrate Polymers, 96(2), 578-85.

Wu, Y., Yang, W., Wang, C., Hu, J., \& Fu, S. (2005). Chitosan nanoparticles as a novel delivery system for ammonium glycyrrhizinate. International Journal of Pharmaceutics, 295(1-2), 235-245.

Xu, Y., \& Du, Y. (2003). Effect of molecular structure of chitosan on protein delivery properties of chitosan nanoparticles. International Journal of Pharmaceutics, 250(1), 215-226.

Yang, S.-J., Lin, F.-H., Tsai, H.-M., Lin, C.-F., Chin, H.-C., Wong, J.-M., \& Shieh, M.-J. (2011). Alginate-folic acid-modified chitosan nanoparticles for photodynamic detection of intestinal 
neoplasms. Biomaterials, 32(8), 2174-2182.

491 Yoksan, R., Jirawutthiwongchai, J., \& Arpo, K. (2010). Encapsulation of ascorbyl palmitate in 492 chitosan nanoparticles by oil-in-water emulsion and ionic gelation processes. Colloids and $493 \quad$ Surfaces B: Biointerfaces, 76(1), 292-297.

494 Zainol, S., Basri, M., Basri, H. Bin, Shamsuddin, A. F., Abdul-Gani, S. S., Karjiban, R. A., \& Abdul-Malek, E. (2012). Formulation Optimization of a Palm-Based Nanoemulsion System Containing Levodopa. International Journal of Molecular Sciences, 13(12), 13049-13064.

Zhao, J., Wei, S., Liu, F., \& Liu, D. (2014). Separation and characterization of acetone-soluble phosphatidylcholine from Antarctic krill (Euphausia superba) oil. European Food Research and Technology, 238, 1023-1028.

500

501

502

Zhu, J., Zhuang, P., Luan, L., Sun, Q., \& Cao, F. (2015). Preparation and characterization of novel nanocarriers containing krill oil for food application. Journal of Functional Foods, 19, 902-912.

503

Zimet, P., \& Livney, Y. D. (2009). Beta-lactoglobulin and its nanocomplexes with pectin as

504 vehicles for $\omega-3$ polyunsaturated fatty acids. Food Hydrocolloids, 23(4), 1120-1126. 


\section{Graphical Abstract}

515

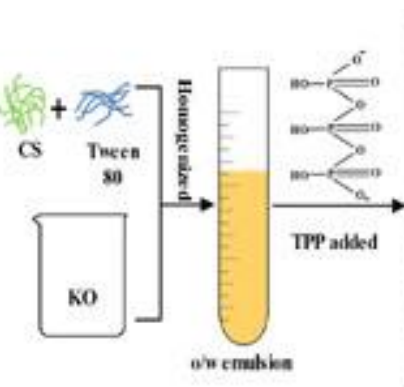

516

517

518

\section{Highlights:}

- KO loaded CSNPs were prepared using emulsion-electrostatic interaction method.

- KO loaded CSNPs were irregular in shape with average diameter of $<130 \mathrm{~nm}$.

- CSNPs successfully entrap KO as evident by FTIR.

- $\mathrm{KO}$ loaded CSNPs prevented formation of hydroperoxides at elevated temperature. 
519 Table 1. Loading capacity (LC) and Encapsulation Efficiency (EE) of KO determined by TGA 520 technique, intensity ration of $I_{2925} / 890$ determined by FTIR technique, and z-average diameter and $521 \zeta$-potential value of CS and KO-loaded CSNPs.

\begin{tabular}{|c|c|c|c|c|c|}
\hline \multirow[t]{2}{*}{$\begin{array}{l}\text { CS : KO } \\
(w / w)\end{array}$} & \multirow[t]{2}{*}{ LC (\%) } & \multirow[t]{2}{*}{$\mathrm{EE}(\%)$} & \multicolumn{2}{|l|}{$\begin{array}{l}\text { Z-average } \\
\text { diameter }^{\mathrm{b}}\end{array}$} & FTIR $^{\mathrm{a}}$ \\
\hline & & & $(\mathrm{nm})$ & $(\mathrm{mV})$ & $\left(I_{2925} / I_{890}\right)$ \\
\hline 1:0.00 & 0 & 0 & $252.0 \pm 4.9$ & $37.7 \pm 0.0$ & 0.91 \\
\hline 1:0.25 & 8.8 & 58.9 & $229.5 \pm 3.9$ & $35.2 \pm 0.2$ & 1.14 \\
\hline $1: 0.50$ & 13.3 & 47.1 & $218.6 \pm 0.3$ & $34.3 \pm 0.9$ & 1.42 \\
\hline 1:0.75 & 18.7 & 41.8 & $217.6 \pm 2.0$ & $31.0 \pm 0.5$ & 1.60 \\
\hline 1:1.00 & 21.8 & 37.0 & $191.3 \pm 0.2$ & $29.5 \pm 0.2$ & 1.81 \\
\hline $1: 1.25$ & 24.7 & 33.3 & $182.4 \pm 1.1$ & $26.6 \pm 0.4$ & 1.80 \\
\hline
\end{tabular}

522

523

524

525

526

527

528

529
$\mathrm{LC}=($ weight of loaded $\mathrm{KO} /$ weight of sample $) \times 100$.

$\mathrm{EE}=($ weight of loaded KO/weight of $\mathrm{KO}$ in feed $) \times 100$.

${ }^{\mathrm{a}} I_{2925} / I_{890}=$ Indicates the intensity ration of $-\mathrm{CH}$ stretching peak at $2925 \mathrm{~cm}^{-1}$ to pyranose peak at $890 \mathrm{~cm}^{-1}$.

${ }^{\mathrm{b}}$ Indicated values are reported as means \pm standard deviation $(n=3)$ 


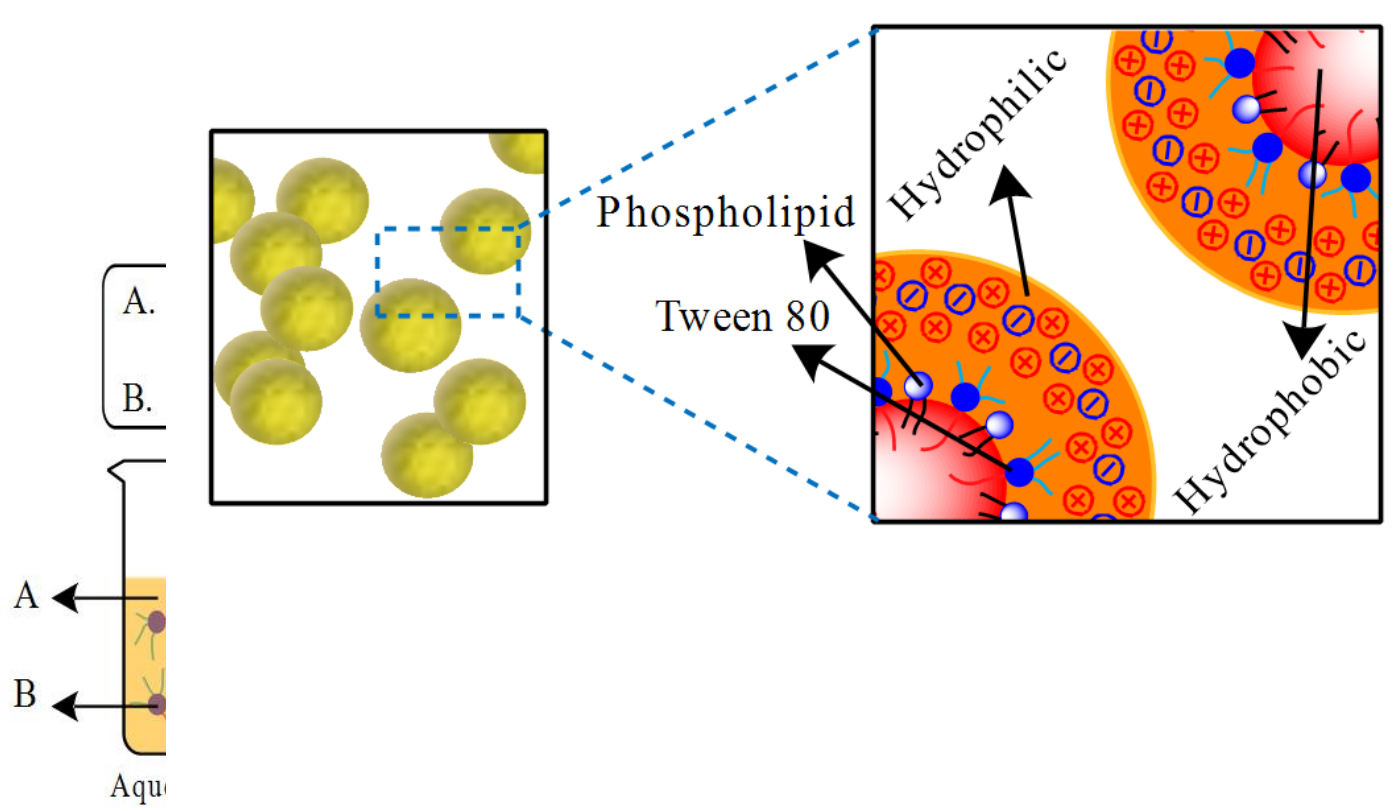

Figure 1. Schematic illustration of KO-loaded CSNPs prepared by emulsion and electrostatic interaction of CS and TPP. O/W emulsion was stabilized by synergistic effect of two amphiphiles (i.e., tween 80 and phospholipids inherent in KO) in term of emulsification. A cartoon of formed KO-loaded CSNPs (inset) indicates the entrapment of oil droplet by absorption of surfactant molecules with their hydrophilic portions (light blue and dark blue of phospholipids and tween 80 respectively) oriented toward the aqueous phase and their hydrophobic portion (black and red of phospholipids and tween 80 respectively) anchored in the oil. 


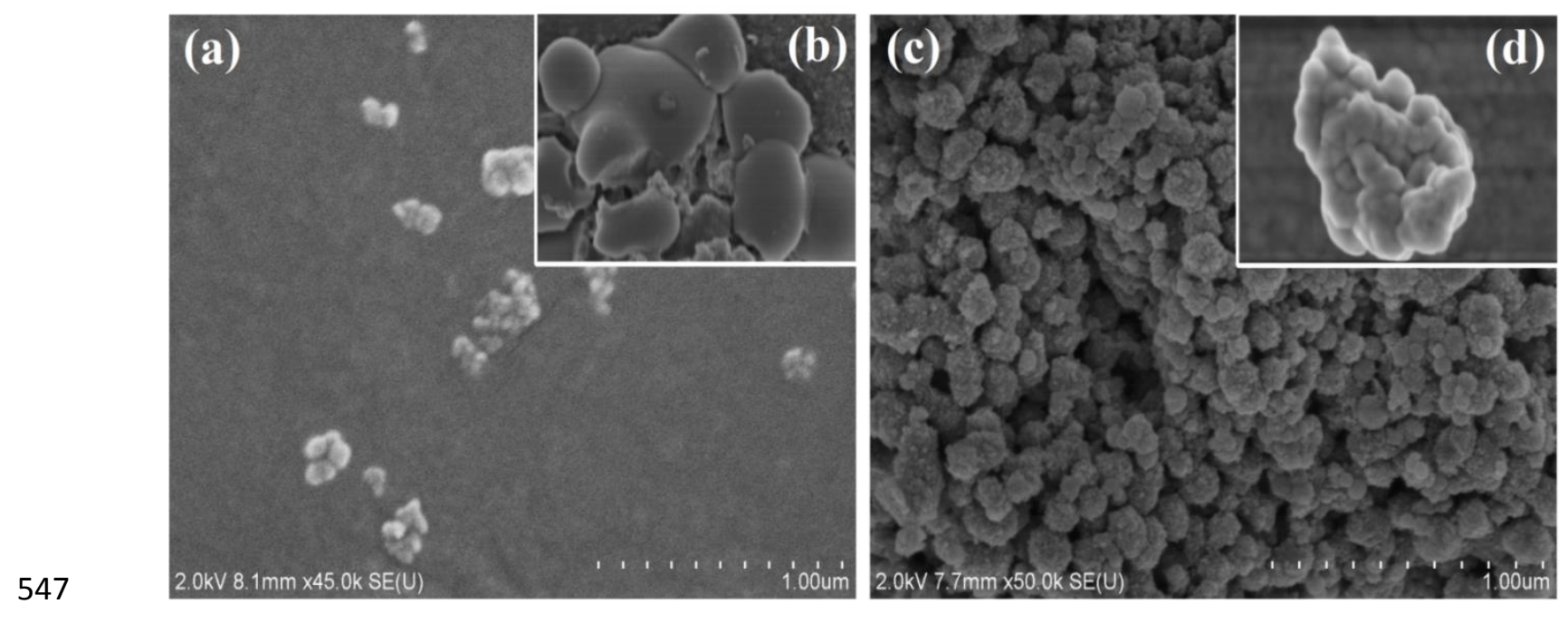

548 Figure 2. SEM micrographs at $2 \mathrm{kV}$ of (a and b) CSNPs and (c and d) KO-loaded CSNPs 549 prepared using an initial weight ratio of CS to KO of 1:1.00.

550 
Figure 3. Z-average diameter, PDI and $\zeta$-potential of CSNPs and KO-loaded CSNPs with

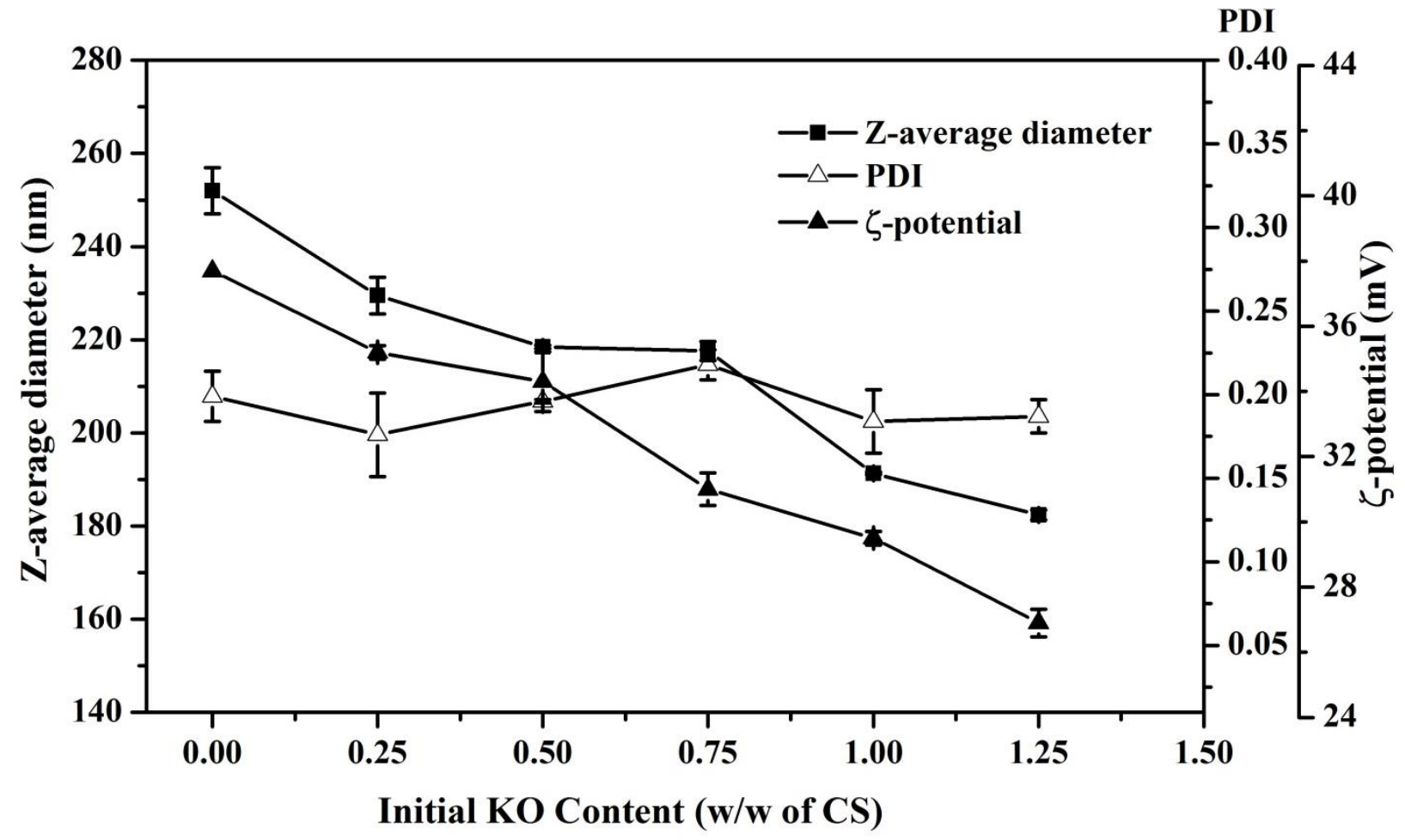

554 different CS to KO weight ratios. Indicated values are the means \pm standard deviation $(n=3)$. 


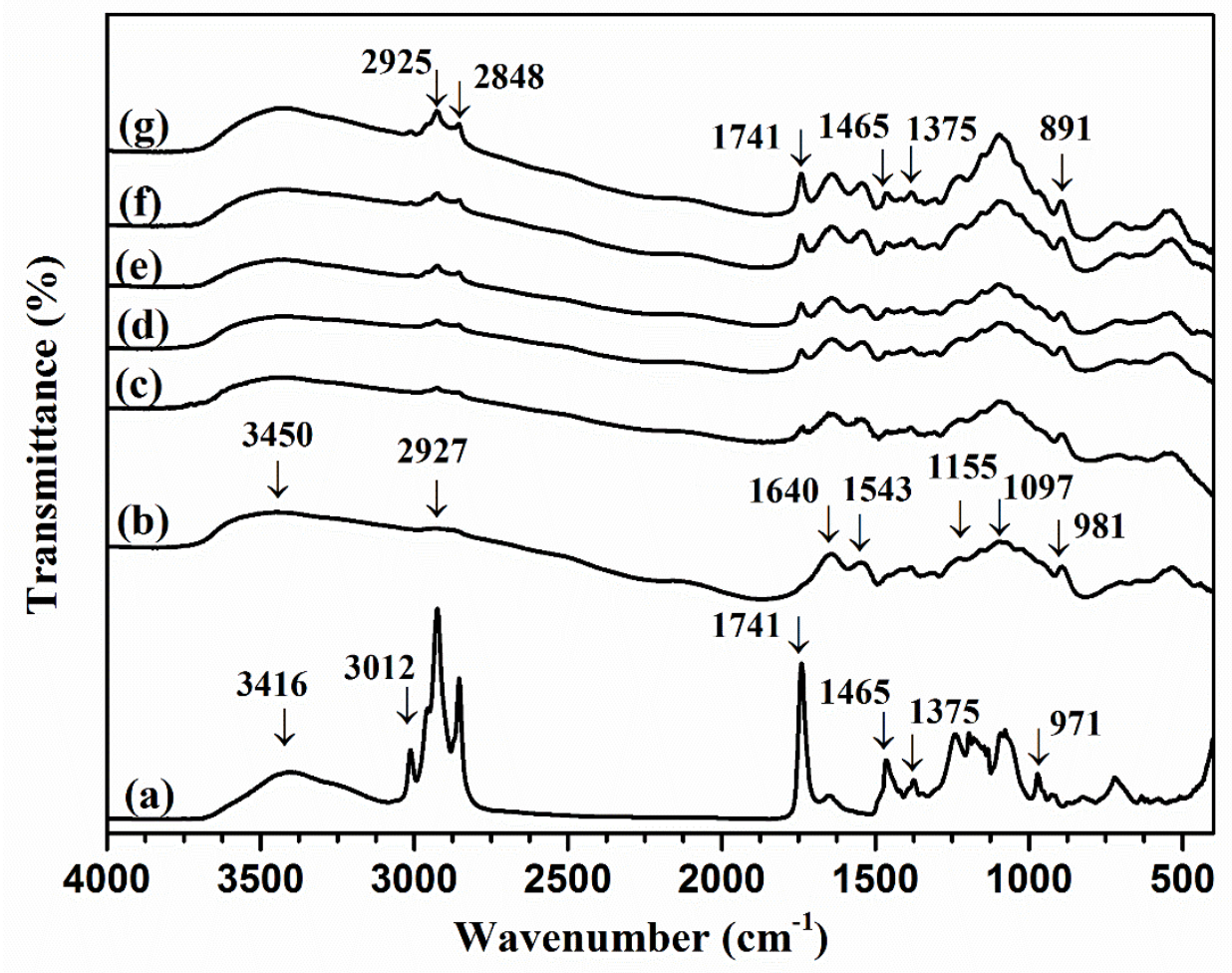

Figure 4. FTIR spectra of (a) KO, (b) CSNPs and (c)-(g) KO-loaded CSNPs prepared using 

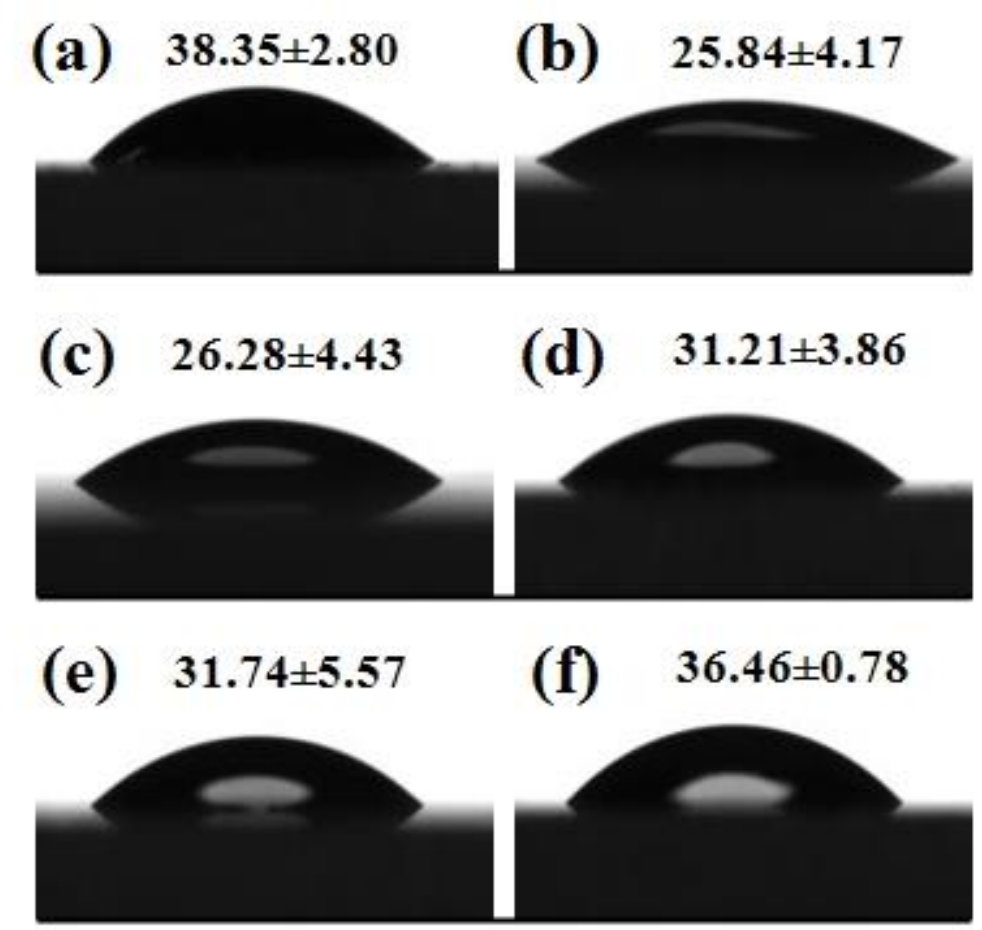

(g) $36.02 \pm 4.21$

564 Figure 5: The surface contact angle values of (a) KO, (b) CSNPs and (c)-(g) KO-loaded CSNPs 565 prepared using different CS to KO weight ratios: (c) 1:0.25, (d) 1:0.5, (e) 1:0.75, (f) 1:1, (g) $566 \quad 1: 1.25$ 


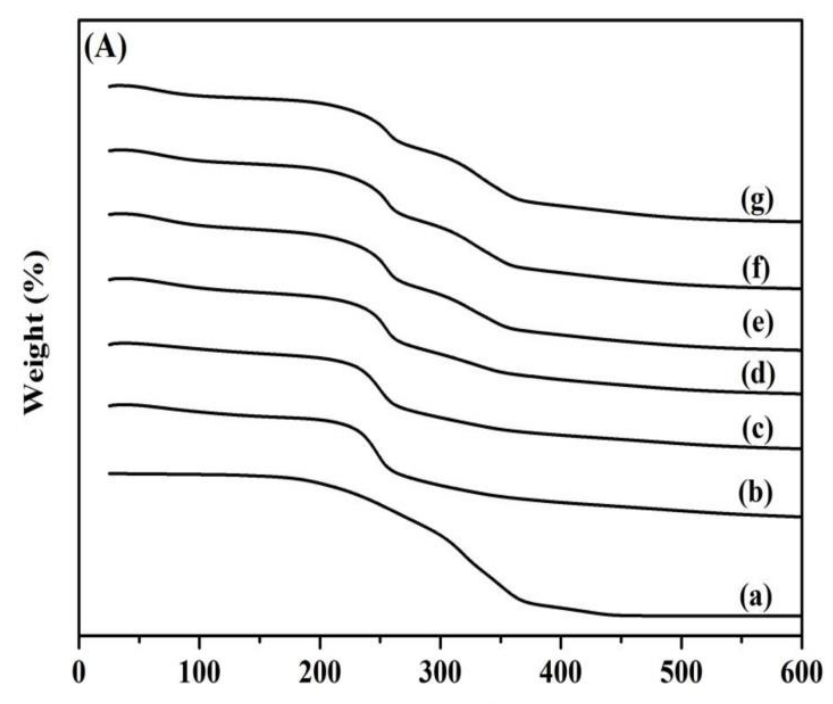

Temperature $\left({ }^{\circ} \mathrm{C}\right)$

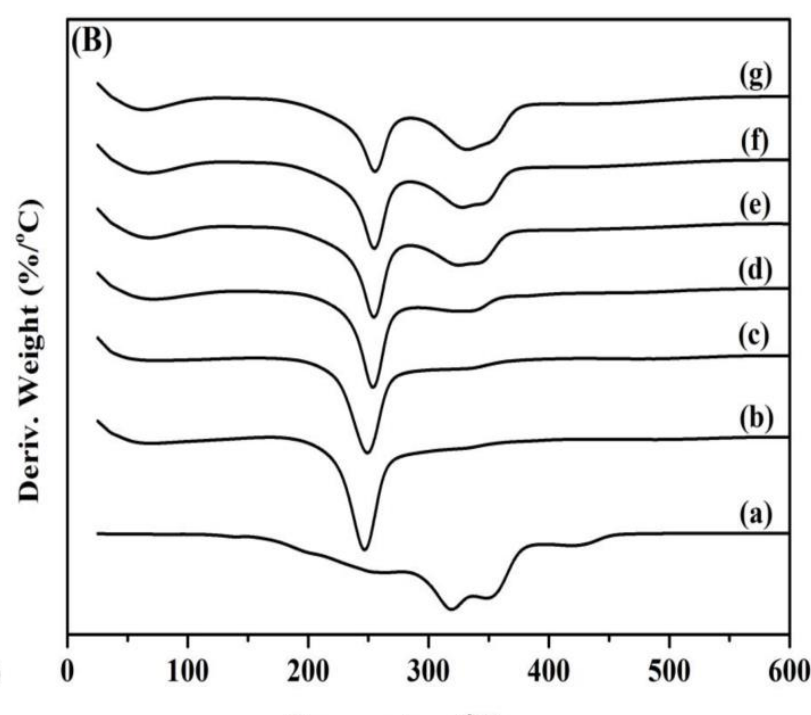

Temperature $\left({ }^{\circ} \mathrm{C}\right)$
572

573

574

575

576

577

Figure 6. (A) TGA and (B) DTG thermograms of (a) KO, (b) CSNPs and (c)-(g) KO-loaded CSNPs prepared using different CS to KO weight ratios: (c) 1:0.25, (d) 1:0.50, (e) 1:0.75, (f) $1: 1.00,(\mathrm{~g}) 1: 1.25$.

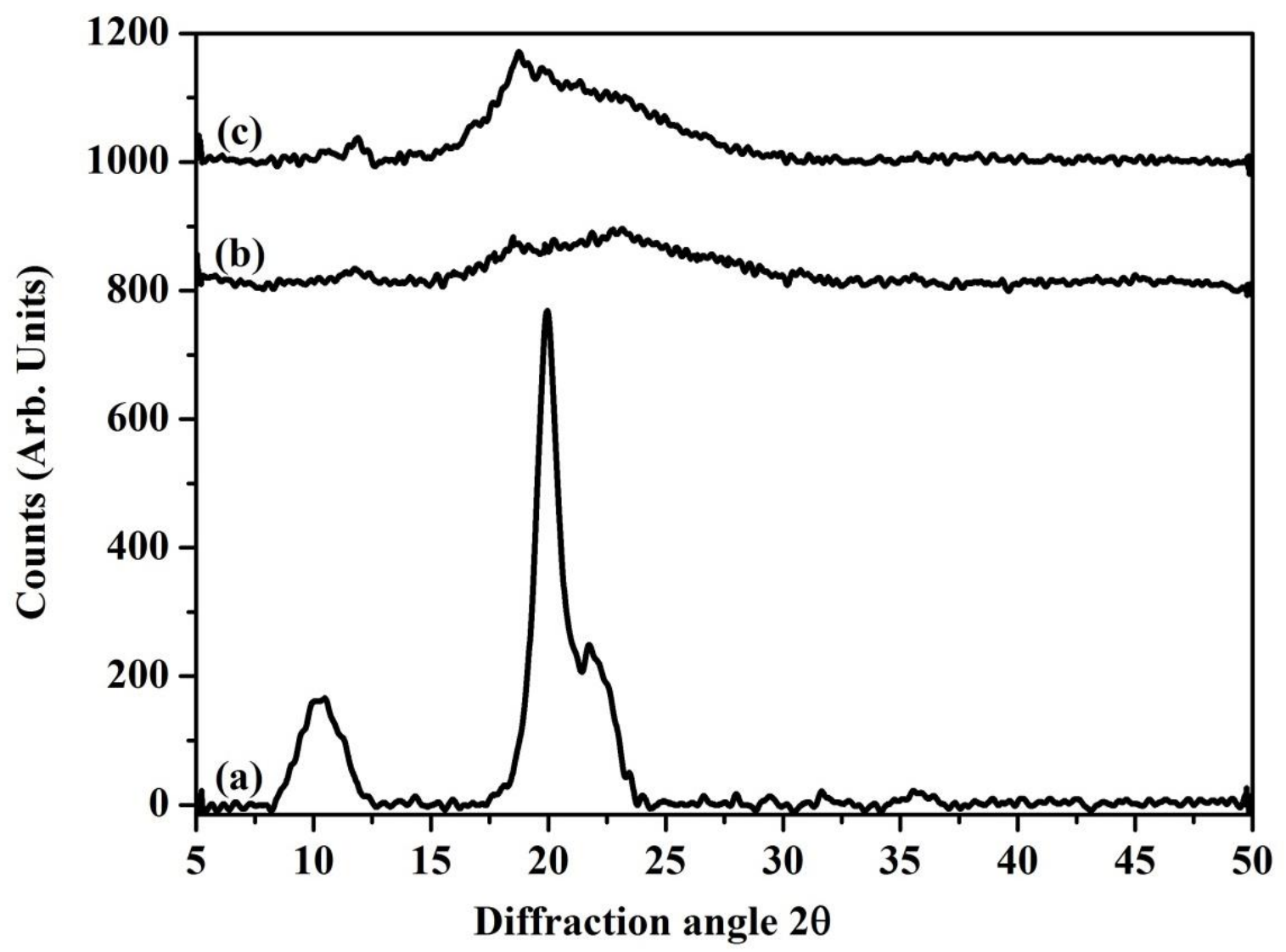


Figure 7. XRD patterns of (a) CS powder, (b) CSNPs and (c) KO-loaded CSNPs.

(A)
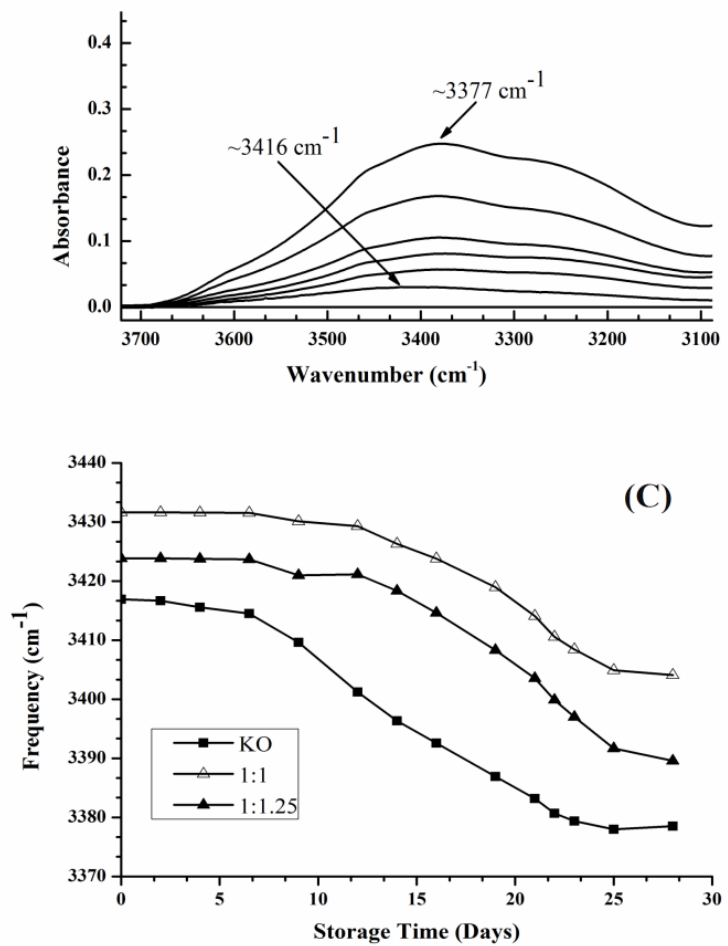
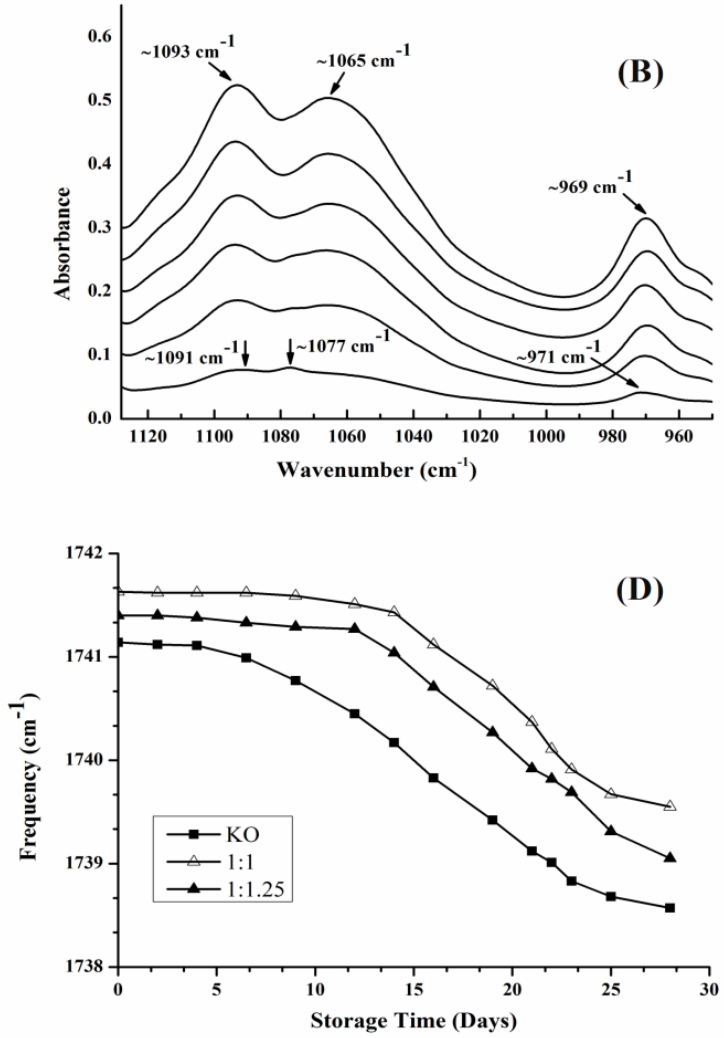

582

583

584

585

586

587

588

Figure 8. Time series differential spectra of $\mathrm{KO}$ and KO-loaded CSNPs during storage at $45^{\circ} \mathrm{C} /$ 4 weeks: (A) ROOH region of $\mathrm{KO}\left(\sim 3416\right.$ to $\left.\sim 3377 \mathrm{~cm}^{-1}\right)$ absorptions, (B) CO region ( $\sim 1091$ to $\sim 1093 \mathrm{~cm}^{-1} \& \sim 1077$ to $\left.\sim 1065 \mathrm{~cm}^{-1}\right)$ and trans region of $\mathrm{KO}\left(\sim 971\right.$ to $\left.\sim 969 \mathrm{~cm}^{-1}\right)$ (C) Frequency values of band near $\sim 3416 \mathrm{~cm}^{-1}$ (D) Frequency values of band near $\sim 1741 \mathrm{~cm}^{-1}$. 